\title{
Translating Technology, Science and Health: \\ Public Information Officers as \\ Knowledge Transfer Intermediaries
}

\section{Assistant Professor, Judith McIntosh White, University of New Mexico, USA}

\begin{abstract}
PIOs (PIOs) link transfer of technology/science/health knowledge between researchers and journalists. PIOs' orientation toward acquiring technology/science/health knowledge is important to PIOs' choices of education, training, and occupational experience. The purpose of this study was (1) to conceptualize a way to measure such orientation, using descriptive data from an Internet survey of a random sample of PIOs to construct an exploratory scale to measure technology/science/health orientation (TSHO) and (2) to test the constructed TSHO scores as predictors of PIOs' job performance. Results showed respondent PIOs' calculated TSHO scores to range from 0 to 5 (out of a possible maximum of 6), with a mean of 2.38 and a mode of 2. TSHO score was a statistically significant predictor for variety of story topics covered by PIOs but not of number of scientist sources used in their information subsidies. Further research and analysis are needed to validate scale construction and to test its predictive ability across additional samples.
\end{abstract}

Keywords: science PIOs, health PIOs, science orientation, knowledge transfer, coverage predictors 


\section{Introduction}

Concern over the status of science literacy in the United States prompted the American Association for the Advancement of Science in 1985 to launch Project 2061, a "long-term initiative to help all Americans become literate in science, mathematics, and technology" (AAAS, 2009). Project 2061 has comprised a number of research studies, yielding blueprints for accomplishing this goal. Part of the AAAS initiative included outlines for more effectively using mass media to communicate science to the public.

And to some extent, mass media have accepted that role. Reporters may see themselves as agents mediating information between scientists and experts and the public. However, some researchers have found media either incompetent to transmit information about issues as complex as global warming or introducing confusion about it; such researchers feel the media can be trusted to communicate only simple ideas (Meyer, 2006). Mormont and Dasnoy (1995), for example, recommend more active roles for expert sources in interpreting science: "The construction of news involves the commitment of actors - mainly experts - and the development of a framework of reference" (p. 63).

The public remains interested in science stories in the mass media. Polls indicate 4 of 10 people actively seek out science news (McInerney, Bird, \& Nucci, 2004). But the media is not meeting that expressed need for science information. For example, the amount of science coverage in newspapers, both in numbers of stories and column inches, declined over the past decades (Hays, 1993; Project for Excellence in Journalism, 2008), and media in general have downsized by laying off science reporters and tried to save money by eliminating science sections (Brainard, 2008-9; Calamai, 2008; Project for Excellence in Journalism, 2008). Although 96 U.S. newspapers had science sections in 1990, only 47 had them two years later (Nordstrom, Wilson, Richards, Coe, Fivek, \& Brown, 1999). By 2008, newspaper science sections numbered 35, most now focusing on health and fitness (Project for Excellence in Journalism, 2008). Other factors contributing to this decline include indications consumers and scientists may not turn to newspapers as the preferred medium for science information (Bruening \& Martin, 1992; Bruening, Radhakrislma, \& Rollings, 1992; Bruno \& Vercellesi, 2002; Oskam, 1992) and that most newspaper reporters possess low levels of science literacy (Haygood, Hagins, Akers, \& Keith, 2005). Existing science coverage often concentrates on controversy and risk, with few positive stories (Beaudoin \& 
Thorson, 2004; Rhomberg, 2009; Ten Eyck, 2000). Other researchers note newsworkers' routines and newsrooms' structures discourage covering science news (Logan, 2001).

Perhaps because of these developments, scientists themselves despair about using mass media to convey results of their research. Frequently, they bypass mass media and speak directly to the public themselves, although effectiveness of such an approach remains problematic (Holland, 2009; Morelle, 2005; Peters et al., 2008; Sachsman, 1993). PIOs (PIOs) at institutions where scientists work usually act as intermediaries between mass media and scientists, working distribute research stories (Anderson, Peterson \& David, 2005; Bauer \& Bucchi, 2007; Triese \& Weigold, 2002). PIOs' distribution efforts usually comprise information subsidies such as news releases, the institution's Website, and direct contacts with reporters and editors to offer scientists as story sources ("making pitches") (Wilcox, 2005). Gandy, in his seminal work on reporters' using information subsidies as story sources (1982), and Calamai (2008) note that information subsidies underlie 50 to 90 percent of mass media stories.

If mass media, even with its current problems, is an important channel by which scientists communicate their work to the public (Peters, 2009) and if PIOs are a crucial link in that chain, then the more that PIOs know about science, the better they will be able to communicate with scientists and the more effectively they can translate scientists' work for mass media (Allan, 2005). However, because many PIOs receive a traditional journalism or public relations education, they may lack significant knowledge and skills which would enhance their abilities to speak with scientists. Such lack of science knowledge and skills may indicate PIOs are not oriented toward technology, science, and health and do not seek to acquire the expertise needed to effectively transfer such information from researchers at their institutions to mass media. This study addresses the technology/science/health orientation (TSHO) of PIOs and attempts, first, to construct an index measuring such orientation, then to investigate the extent to this index correlates with aspects of PIOs' roles in the knowledge transfer process. 


\section{Review of Literature}

\section{Theoretical framework for communicating technology, science and health to the public}

Mass media news forms an important channel for the transfer of knowledge between scientists and the public (Nisbet \& Scheufele, 2009; Peters, 2009). Institutional PIOs function as intermediaries in that process, interfacing with scientists and authoring information subsidies to publicize and explain research to mass media reporters and editors (Katz, 2004). However, fundamental constraints inhibit such knowledge transfer, among them that scientists and journalists (including PIOs) do not speak the same language and cannot easily understand each other (Morelle, 2005; Sachsman, 1993). These constraints can be analyzed based on principles of successful knowledge transfer and the theories journalists use to construct news coverage.

Knowledge transfer from institutional scientists to the public through mass media, with PIO intermediaries, may be represented by the following model:

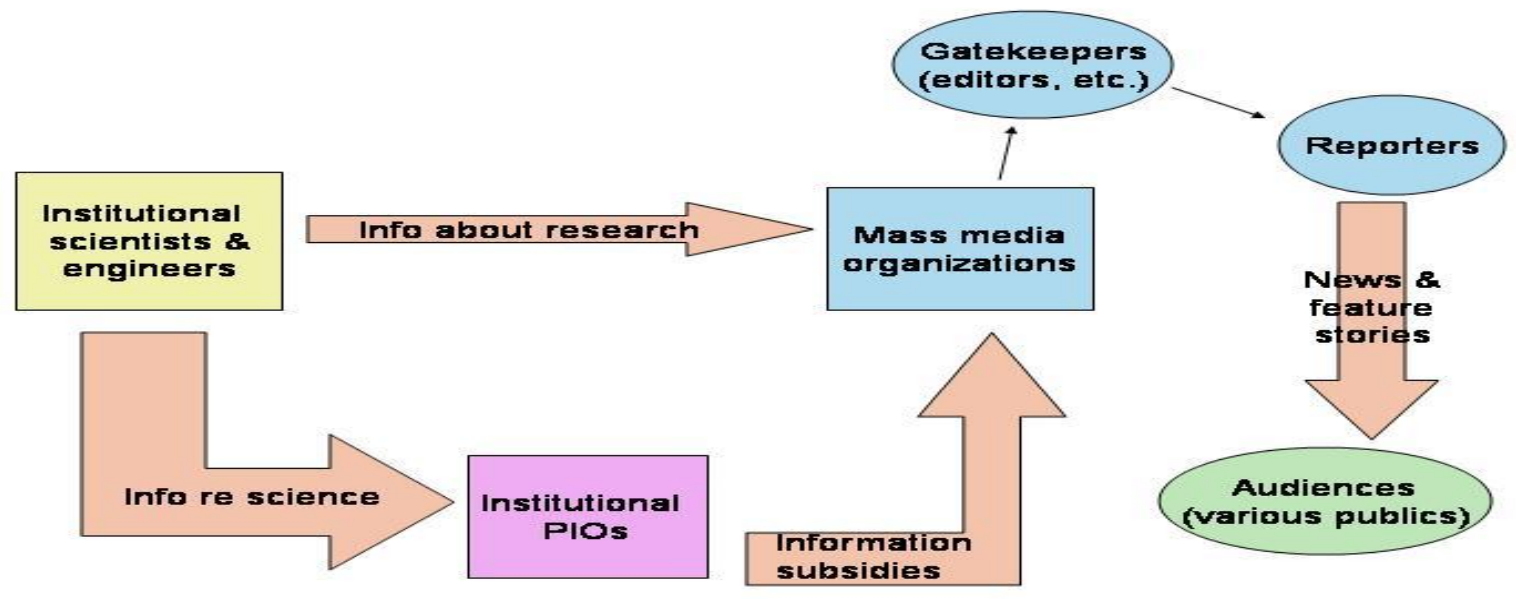

Figure 1: Conceptual Model of Knowledge Transfer from Institutional Researchers to the Public through Institutional PIOs and Mass Media Journalists

This model posits institutional PIOs as necessary go-betweens precisely because scientists and reporters communicate differently (Morelle, 2005; Peters et al., 2008; Sachsman, 1993). Successful knowledge transfer depends on common understanding to build apprehension of new concepts, expressed in mutually understood language (Levin, Cross \& Abrams, 2002). Shared foundational knowledge and mutually understood language build trust, shown to be necessary for knowledge transfer to occur (Levin, Cross \& Abrams, 2002). Influencing 
journalists' decisions about which technology/science/health stories merit coverage are theories of agenda-setting and framing and resulting standards for information sourcing.

Opinion leaders help define issues about which the public should think (Dearing \& Rogers, 1996; McCombs \& Shaw, 1976; McQuail, 1994; Rogers \& Dearing, 2000), and media communicate agenda salience, through a process explained theoretically as agenda-setting. The theoretical concept of framing guides the public as to how it should think about a particular issue. Framing provides context for opinion formation and discussion (DeFleur \& Ball-Rokeach, 1989; McQuail, 1994; Reber \& Berger, 2005). Frames developed by reporters help the public construct schema to place issues into understood and shared contexts (McQuail, 1994; Reber \& Berger, 2005). Media frames contribute to individual and societal construction of meaning out of larger events (DeFleur \& Ball-Rokeach, 1989; Reber \& Berger, 2005) and may best exert their intended effect by focusing on audience self-interest, for example, how to avoid a perceived threat (Rodriquez, Farnall, Geske, \& Peterson, 1998). Journalistic frame-building is influenced both by the ideology, attitudes, and professional norms of individual reporters and by their organizational routines (Scheufele, 1999). Reporters themselves are susceptible to agenda setting and framing of issues by the coverage of stories in media regarded as particularly prestigious and credible, i.e., the "news wave" (Breed, 1955; Dunwoody, 1979, 1980; Havick, 1997; Ten Eyck, 2000).

Story frames are built around reporters' concepts of newsworthiness, comprising factors like conflict and proximity, as well as reporters' sense of stories' contextual salience. Agendasetting and arterial effects (Breed, 1955) generated may force reporters to adopt others' frames via consulting the same or similar sources. Frame establish associative pathways between target issues and specific sets of concepts. By activating or suggesting some ideas at others' expense, news can encourage particular trains of thought about political phenomena and lead audience members to more or less predictable conclusions. Framing, or rendering certain thoughts applicable, is most likely to occur when suggested ideas are relatively accessible prior to exposure (Tewksbury, Jones, Peske, Raymond, \& Vig, 2000.

Selecting and seeking out sources for information to construct stories is a job function common to all reporters. It is axiomatic that reporters report the news; they do not make it. In their role as "eyewitnesses to history," certain types of reporters (war correspondents, 
sports writers) bring their readers first-person accounts of what they themselves see, hear, or otherwise experience. However, most reporters craft accounts of events happening outside of their immediate experience; they must seek out others to tell them about such occurrences and to help interpret what events mean to the public (Heinrichs \& Peters, 2004; Simonson, 1999). Such others are called sources, and reporters try to choose the best sources for a given story, based on the source's institutional position, knowledge, accessibility, or cooperativeness, or some combination of these characteristics

By definition, technology/science/health experts (engineers, scientists, physicians) constitute the best sources about science. In covering stories dependent on understanding scientific principles, reporters' abilities to identify and successfully use appropriate news sources are paramount to effective, reliable news coverage. Such complex stories lie outside everyday experience of most reporters and require knowledge beyond their usual education. Identification of knowledgeable sources and scrupulous attribution of information provided is crucial to accurate telling of these stories (Albaek, Christiansen, \& Togeby, 2003). Not only must reporters involved with such coverage not fabricate information or sources, they must identify and accurately report the "right" sources to explain such matters to audiences (Lee, 2004).

Researchers note that coverage by technology/science/health specialty-beat reporters differs from that by general assignment reporters in quantity, type, and tone (Craft \& Wanta, 2004; Long, 1995; Shoemaker, Eichholz, Kim \& Wrigley, 2001). Other studies on relationships between specialty-beat reporters and sources found such reporters often use the same sources continually, building strong bonds with them, (Chermak, 1995; Dunwoody, 1979, 1980; Gandy, 1982; Ten Eyck, 2000) and often focus almost exclusively on dependable institutional representatives (Ericson, Baranek, \& Chan, 1993; Sumpter \& Braddock, 2002). Other researchers call for media to concentrate more on experts as sources for complex stories (Cassidy, 2004; Ramsey, 1999), although they note that reporters' ability to deal effectively with expert sources may depend upon their own technology/science/health training (Grantham \& Irani, 2004; Vestal \& Briers, 1999; Wingenbach, Rutherford, \& Dunsford, 2003). Often an intermediary is needed to translate experts' work into terms understandable by reporters with little science training - hence, the importance of competent PIOs to fill that role. Reporters cannot use as sources experts they cannot identify access or understand. 


\section{PIOs' role in mass media technology/science/health coverage}

PIOs' role in mediating between mass media editors and reporters and institutional scientists has been recognized by communication researchers (Anderson, Peterson \& Davis, 2005; Bauer \& Bucchi, 2007). Campus agricultural communicators (a particular type of institutional PIO) potentially could raise reporters' scientific literacy through PIO information subsidies by influencing interactions between reporters and university experts; such communicators' credibility with and accountability to both faculty clients and media's public audiences emerge as crucially important (King, 1991).

Other studies highlight links between media coverage and public acceptance of technological innovations in agriculture like biotechnology (Besley \& Shanahan, 2005). But to report about such innovations, reporters must have an adequate knowledge base from which to interact with experts. Technology/science/health specialty-beat reporters strive to be objective, but do best when they understand the topics about which they write; such reporters may form "their perceptions about biotechnology through knowledge and experience (science classes and labs), which is conducive to understanding and reporting accurately the science of biotechnology" (Wingenbach, Rutherford, \& Dunsford, 2003, p. 1).

Researchers agree coverage depends on media levels of technology/science/health literacy (Haygood, Hagins, Akers, \& Keith, 2005), with specialty reporters interpreting their subject areas more narrowly and being more likely to consult experts (Anderson, Peterson \& Davis, 2005; Bauer \& Bucchi, 2007; Dunwoody, 1978). Reporters' and editors' agricultural literacy levels play an important part in their explaining science in their stories when only $20 \%$ of the public meets basic definitions of scientific literacy (Haygood, Hagins, Akers, \& Keith, 2005).

Clearly, PIOs form important links in knowledge transfer between institutional scientists and engineers and the public, through mass media, especially given the low levels of technology/science/health literacy possessed by both journalists and audiences. However, PIOs themselves must become educated in the language and principles of technology/science/health to successfully fulfill that role. Criticisms of media technology/science/health coverage and of PIOs' performance as intermediaries illustrate the need for such education. 


\section{Criticisms of media coverage of science and of PIOs' performance as intermediaries}

Scientists themselves understand the importance of communicating with the public, "frequently working the media themselves, in order to make arguments that cannot be aired via everyday academic communication routes such as journal stories or to reach audiences outside their own discipline" (Cassidy, 2004, p.3). And reporters see scientists as particularly credible sources (Heinrichs \& Peters, 2004) and themselves as information intermediaries between such experts and the public.

However, critics of journalists' science coverage charge that the media either are incompetent to transmit information about science issues as complex as global warming or they introduced confusion about it (Meyer, 2006; Mormont \& Dasnoy, 1995). Such critics recommend a more active role for expert sources in interpreting science for the public.

And researchers Heinrichs and Peters (2004) cautioned that reporters frequently may decontextualize source comments by eliminating descriptions of surrounding circumstances and of the sources themselves. Other researchers cite a journalistic practice of "rel[ying] heavily on unnamed sources (proponents, experts, environmentalists, etc.) and poorly identified advocacy groups" (Beall \& Hayes, 1992, p. 6).

Some critics of media technology/science/health coverage and PIOs' information subsidies believe it would be most productive to teach news sources to interact better with media, because in their opinion no amount of training can turn reporters into scientists (Sachsman, 1993). A number of scientists in fact see themselves as working well with the media (Valenti, 1999); they do not fear being misquoted and "generally found media people competent, professional and pleasant to work with," and said "they use the news media because they can reach many people fast, effectively and economically" (Sperbeck,1997, p.24). Thus, the literature reflects the concern that mass media science coverage needs improvement and that ways must be found to improve communication between scientists and journalists, although just how this can be done is debatable.

\section{Study Objectives}

This study explores the idea that improving PIOs' knowledge transfer abilities could result in improving mass media technology/science/health coverage. Crucial to PIOs' knowledge 
transfer competency is improving their grasp of basic principles underlying technology/science/health research. PIOs' orientation to technology, science and health their inclination toward acquiring expertise about such subjects -- may be an important determinant of knowledge acquisition and serve as a proxy measurement for knowledge levels.

Although researchers have studied science communication and attributes of its practitioners, some even accessing the same population as this study (Triese \& Weigold, 2002; Cooper \& Yukimura, 2002), none have attempted to evaluate the impact of a composite technology/science/health orientation on PIOs' attitude formation and practice. This study focuses on investigating this orientation and constructing an index measuring this composite attribute.

The study sought to answer the following general research questions:

RQ1: What are salient attributes, including education and training and experience in science and technology/science/health journalism, of PIOs engaged in the communication of technology/science/health information to the public through reporters?

RQ2: Is there a detectable orientation toward technology/science/health among such PIOs?

RQ3: Can such an index predict aspects of PIOs' information subsidies, such as variety of types of news releases written and numbers of scientist sources used in these releases?

The following hypotheses were tested:

H1: The higher a PIO's TSHO index, the greater the number of different types of science/health/ technology news releases produced by such a PIO.

H2: The higher a PIO's TSHO index, the more times that PIO will choose scientists are sources for his/her news releases.

\section{Methods}

\section{Study design, population of interest and sample.}

Data for this paper was extracted from responses to an online survey of samples from two subpopulations selected from members of the National Association of Science Writers (NASW). This broader study provided a comprehensive picture of characteristics, attributes and attitudes of sample members, which can be generalized to the subpopulations involved 
and may be hypothesized to describe a larger universe of technology, science and health writers/reporters and PIOs seeking to influence them.

NASW members constitute the population of interest. NASW is one of the United States' oldest and largest professional organizations dedicated to the advancement of technology/science/health journalism. Membership is restricted to journalists and PIOs demonstrating active involvement with technology/science/health communication information through providing work samples and recommendations from two current NASW members. NASW has approximately 2,900 members, divided into two subpopulations of reporters/writers (approximately 1,500) and PIOs (approximately 1,400) according to employment information supplied to NASW.

Two samples, one each of reporters/writers (306) and PIOs (249) (Barlett, Kotrlik \& Higgins, 2001), were randomly selected from a list of member names and email addresses (after elimination of members without email addresses) for administration of occupation-specific online surveys. Surveys were mailed to all members (approximately 100 for each group) without email address. This article reports only responses from PIO respondents.

\section{Data collection, response rates and data analysis}

The original online survey instrument was administered to each sample using Dillman's modified five-iteration survey method (Dillman, 2000), designed to increase response levels. Survey coding provided for data to be loaded automatically into a Microsoft Access database as each respondent hit the "submit" button on the survey. Once a respondent's data had been loaded into the database, all identifiers were removed from his/her entry. Data from returned mail questionnaires was manually entered into the same database, and all identifiers similarly were removed from these responses. Upon completion of survey administration, data was transferred to SPSS software for statistical analysis.

Survey recipients could opt out of the study, and 57 PIOs did so. In addition, 28 PIO email addresses were not operational. Thus, the total number of potential PIO respondents was 154 (Field, 2009; Ott \& Longnecker, 2001). Of these potential participants, 99 valid completed questionnaires were received, for an effective response rate of 64.3 percent. 


\section{Findings}

Completed questionnaires yielded information about PIO members of NASW, including demographic characteristics; attitudes technology/science/health public information; work products produced; workplace characteristics; and attitudes toward NASW itself. However, this article focuses on those attributes pointing toward the existence of a career path for PIOs, which taken together make up their orientation toward technology/science/health, an orientation contributing to their attitudes, work products, workplace choices, and dispositions toward NASW.

Therefore, descriptive statistics are presented below for the following PIO attributes: level of education, college major, additional training, years in technology/science/health communication, years in NASW, and specialization in technology, science or health public information. A conceptual model hypothesizing these attributes as forming a composite measure of an individual PIO's technology, science and health orientation (TSHO) is presented, followed by statistics showing the resulting index's ability to predict variety of news releases written and numbers of scientist sources used in these releases.

\section{Descriptive results}

PIOs responding to the survey were an educated group, with 98 percent of them having college or advanced degrees. The majority of respondents had earned masters degrees (50 percent), with 38 percent holding bachelors degrees, 10 percent having doctorates, and 1 percent having earned professional degrees. The majority of respondents (59 percent) majored in journalism (31 percent), fields related to technology, science or health (20 percent), or science journalism (6 percent).

Almost half (48 percent) of respondents had received special training, in addition to their formal education, or additional occupational experience that helped them fulfill their job duties. Types of additional training completed primarily included journalism, science journalism or science coursework separate from college major. Occupational experience seen as helpful to a technology/science/health public information career included work as a journalist, a scientist or healthcare professional, and a university instructor in journalism, science, or health. 
Respondents were experienced PIOs, with 89 percent of them having six or more years in the field. The majority of respondents (54 percent) were clustered between six and 15 years of membership in NASW.

The majority of respondents (79 percent) reported having occupational specialties in science (60 percent), health ( 9 percent), technology ( 3 percent) or some other related field ( 7 percent), including bioethics and writing about clinical trials, HIV/AIDS, geosciences, and history of science.

\section{Conceptual model}

The idea of constructing an index summarizing PIOs' orientation to technology, science and health is exploratory. Figure 2 represents a conceptual model of the possible composition of one such constructed index.

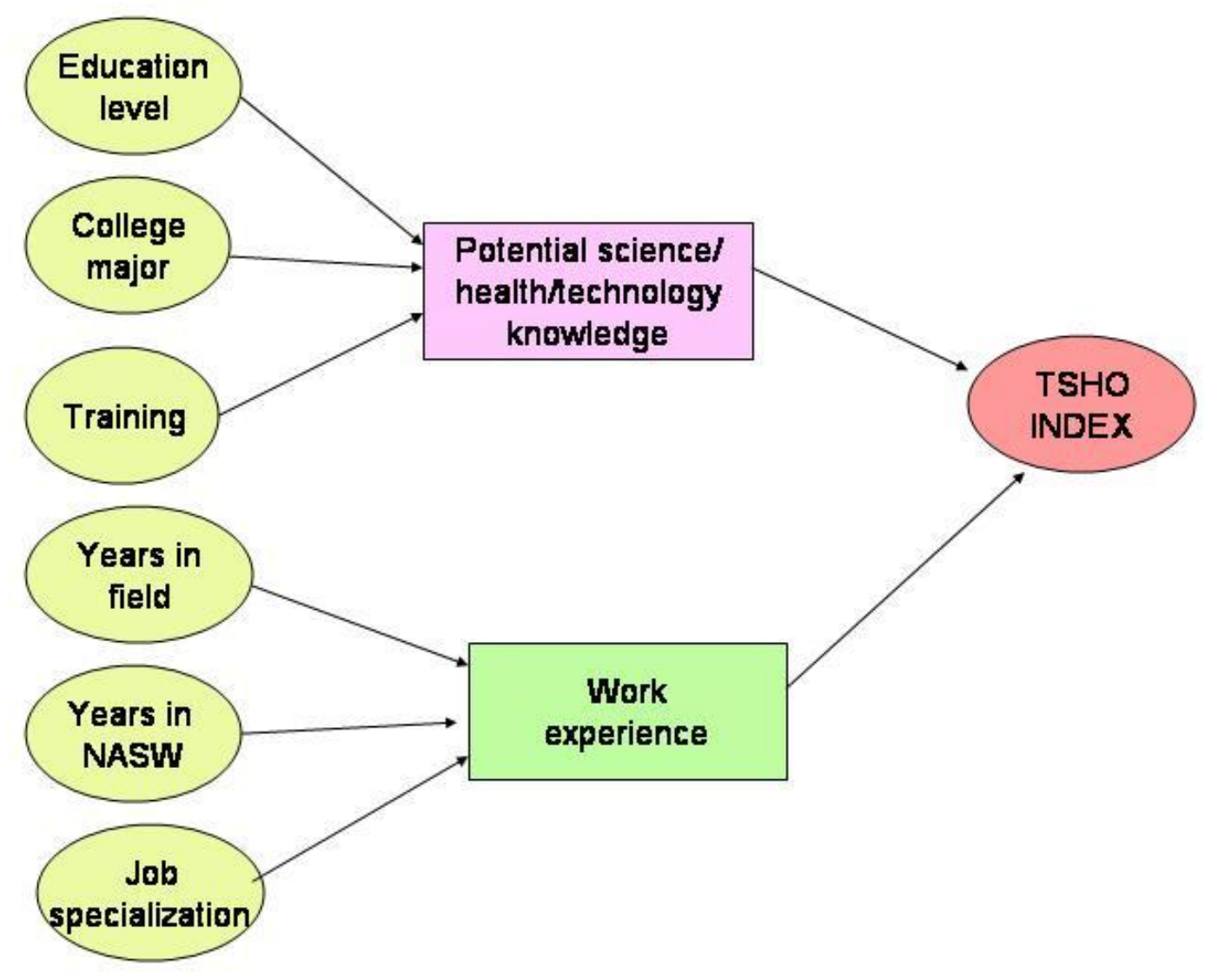

Figure 2: Components in Construction of Composite TSHO Index for PIOs 


\section{TSHO of PIOs}

Originally, ordinal values were assigned to education level, college major, additional training and job specialization; interval values were collected for tenure in the field and in NASW. During analysis, each variable was recoded as a binary nominal value as follows: education, less than bachelors degree $=0$, bachelors degree and above $=1$; major, any major other than science or science journalism $=0$, science or science journalism $=1$; additional training, no $=$ 1 , yes $=1$; technology/science/health job specialization, no $=0$, yes $=1$; tenure in field, less than mean $(15$ years $)=0$, mean or greater $=1$; and membership years in NASW, less than $(10$ years $)=0$, mean or greater $=1$. The TSHO index was then calculated for each public information officer as follows:

\section{TSHO Index = Education + college major + additional training + years in field + years in NASW + job specialization}

Respondent PIOs' calculated TSHO indices ranged from 0 to 5 (out of a maximum of 6), with a mean of 2.38 and a mode of 2 . Index scores were distributed as follows: 0,4 percent; 1, 19 percent; 2, 36 percent; 3, 23 percent; 4, 12 percent; 5, 6 percent; and 6, 0 percent.

\section{Relationship of TSHO index to variety of news releases written}

Survey respondents were provided a list of 22 different technology, science and health news release topics, based on newspaper, broadcast and Internet coverage during the three-month period immediately prior to survey administration. Respondents indicated whether they had written on each topic by checking either "yes" or the "no". The list of topics and the numbers of respondents covering each is shown in Table 1.

Table 1. Topics on which news releases were written by NASW survey respondents.

\begin{tabular}{|l|l|}
\hline TOPIC AREA & $\begin{array}{l}\text { NUMBER OF } \\
\text { WRITTEN } \\
\text { RESPONDENTS }\end{array}$ \\
\hline Air pollution & 17 \\
\hline Autism & 10 \\
\hline Avian flue & 14 \\
\hline BSE/Mad Cow Disease & 5 \\
\hline Cancer & 39 \\
\hline Climate change/global warming & 36 \\
\hline Computer innovations & 31 \\
\hline
\end{tabular}




\begin{tabular}{|l|l|}
\hline Genetically modified foods & 13 \\
\hline Graying of Baby Boomers & 3 \\
\hline Hantavirus & 1 \\
\hline Heart disease/high blood pressure & 28 \\
\hline Hurricane Katrina & 12 \\
\hline Hurricanes/tornadoes/floods & 11 \\
\hline Lead content in toys & 1 \\
\hline Population control issues & 1 \\
\hline Post-partum depression & 6 \\
\hline Post-traumatic stress disorder & 10 \\
\hline Robotics & 22 \\
\hline School shootings & 0 \\
\hline Stem cell research & 30 \\
\hline Women's health issues & 20 \\
\hline World Wide Web & 14 \\
\hline
\end{tabular}

Variety of news releases written by each respondent was obtained by summing "yes" boxes checked. The number of topics written on by a respondent ranged from 0 to 16 , with the mean being 3.24 and the mode being 0 . The distribution for this variable was as follows: 0 news releases on these topics, 35 percent of respondents; 1, 4 percent; 2, 9 percent; 3, 9 percent; 4, 12 percent; 5, 5 percent; 6,5 percent; 7,6 percent; 8,7 percent; 9, 2 percent; 10, 1 percent; 12, 2 percent; and 16, 1 percent.

Analysis of the relationship of variety of topics written upon (dependent variable) and TSHO index (independent variable), both interval level data, using regression and intercorrelation statistical methods, shows that TSHO index is a statistically significant predictor $(p<.05)$ of number of topics written upon $(\mathrm{R}=.224$, $\mathrm{R}$ square $=.050$; Pearson correlation coefficient .224 ; $p=.025)$

\section{Relationship of TSHO index to number of scientists used as sources}

For each of the 22 different technology/science/health story topics written about, the respondent was asked "What source type did you use most often to write your news release?" 
A drop-down menu of 11 source types was provided as follows: activists not from trade/professional associations; business representatives; business scientists, doctors, engineers; consumers/members of the public; government; government scientists, doctors, engineers; state extension; state extension scientists, doctors, engineers; trade or professional association protagonists; university official sources; and university scientists, doctors, engineers.

Responses to this source-type variable were recorded as 0 or 1, with a 1 assigned for each response from one of the "scientist" categories (business, government, state extension or university) and a 0 assigned to all other categories chosen. The number of times a respondent chose a scientist source ranged from 0 to 16 , with the mean being 2.74 and the mode being 0 . The distribution for this variable was as follows: 0 scientists chosen, 43 percent of respondents; 1, 5 percent; 2, 7 percent; 3,12 percent; 4, 8 percent; 5, 6 percent; 6,5 percent; 7, 4 percent; 8, 5 percent; 9, 1 percent; 10, 1 percent; 12, 2 percent; and 16, 1 percent.

Analysis of the relationship of number of scientists used as sources (dependent variable) and TSHO index (independent variable), both interval level data, using regression and intercorrelation statistical methods, shows TSHO index is not a statistically significant predictor $(p>.05)$ of number of topics covered $(\mathrm{R}=.143$, $\mathrm{R}$ square $=.020$; Pearson correlation coefficient .143; $p=.156$ )

\section{Discussion}

Research suggests that to present, explain and interpret experts' information on technology, science and health topics for journalists writing for public audiences, PIOs need to provide more analysis about the relevance and implication of such research (Long, 1995; Steinke, 1995). Such additional information and expanded explication no doubt depend on PIOs' funds of technology, science and health knowledge and understanding. Thus, PIOs ideally should seek specialized education and training, leading to increased knowledge in these fields. Motivation to seek enhanced science-related educational experiences may depend on PIOs' basic orientation toward these knowledge areas.

This article presents an exploratory attempt to construct an index to measure self-identified specialty PIOs' technology/science/health orientation (TSHO score), using data collected in a 
larger inquiry into the characteristics, work products and practices of such PIOs. It provides a preliminary answer to RQ1 by presenting descriptive summaries of data collected about PIOs' education, training, and experience both in technology, science and health and in communication with journalists writing for the public.

Analysis of descriptive data revealed the majority of PIOs had earned masters degrees, majored journalism or in fields related to technology/science/health, completed specialized job training in addition to their formal education, completed six or more years in the field of public information, clustered between six and 15 years of membership in NASW, and specialized in technology/science/health journalism. The fact that 20 percent of study respondents chose to major in fields related to technology, science or health and 6 percent majored in science journalism, while 31 percent majored in "straight journalism," does not, however, make a strong argument for the presence of an elevated degree of motivation toward seeking technology/science/health literacy or toward a elevated orientation to sciencerelated fields among these PIOs.

Application of the proposed TSHO index formula to calculate a unique score for each individual PIO yielded values ranging from 0 to 5 , with a mean of 2.38 and a mode of 2 . Index scores were clustered around 1 (19 percent), 2 (36 percent) and 3 (23 percent), with 78 percent of respondents scoring in this range. Analysis of TSHO scores indicates there may not be a detectable orientation toward technology, science and health among specialty PIOs (RQ2) and does not answer questions about the validity of the formula used to construct the scale nor about the appropriateness of the items chosen for scale inclusion.

Inferential statistical methods (regression and correlation) related respondents' TSHO scores to variety of news releases written but not to use of scientists as sources (RQ3).

The null of H1 cannot be accepted, since the relationship of TSHO index scores to the dependent variable was statistically significant at the $p<.05$ level, with higher TSHO scores correlated with greater numbers of technology/science/health news release topics written upon. The null of $\mathbf{H 2}$ cannot be rejected, since the relationship of TSHO index scores to the dependent variable was not statistically significant at the $p<.05$ level, and higher TSHO scores were not correlated with greater frequency of use of scientists as sources. 
The author realizes that the TSHO index proposed here may be not be extrapolated to samples and populations other than the one in this study. Further, extrapolation of findings may be limited by the fact that the population from which the sample was drawn consists of NASW members. A self-selected group of technology/science/health specialty PIOs apply for membership in this organization, and their applications are subject to approval by the organization itself. Thus, a case could be made that members of NASW are not representative of the larger population of all technology/science/health PIOs.

Despite the limitations of the study, the author believes establishment of a valid and reliable measure of PIOs' technology/science/health orientations is an important endeavor. Such an index and its quantification of PIO education, training and experience could help to guide the education of future technology/science/health PIOs. Improvement in TSHO scores could be tied to improvements in science literacy called for by AAAS and others, through helping PIOs to become more adept at effective transfer of knowledge from those who practice science, health and technology research to journalists communicating with the publics who need and want to understand the results of those endeavors.

Technology/science/health PIOs, who span both journalism and public relations, constitute an important link in the chain of knowledge transfer and serve as a crucial resource for journalists who report to diverse publics. It is vitally important for journalism scholars to assist in the definition of how PIOs may better function in that role and in design and implementation of programs of study aimed at facilitating such improved functioning.

\section{Conclusion}

Technology, science and health journalism and public information have a long history in the United States. Mass media audiences continue to evidence interest in stories produced by technology/science/health journalists, although media outlets have in recent years reduced the amount of coverage and staffing afforded these issues. And such journalism has not, according to numerous researchers, led to the type of informed publics that might have been predicted by its earlier practitioners. 
In fact, concern over the status of science literacy in the United States has prompted AAAS and others to call for more effective use of the mass media to aid in communication of science information to the public. To some extent, mass media has heeded that call, with reporters serving as translators between scientists and other experts and their various publics. And PIOs at institutions where technology, science and health researchers work usually are charged as acting as intermediaries between the mass media and such researchers, with PIOs working to help get out the word about important developments in these fields, in the form of providing editors with information subsidies such as news releases, authoring information for the institution's Website, and direct contact with reporters and editors to offer them the institution's researchers as sources for stories on important issues.

This study indicates that many PIOs already possess some specialized education and training that helps them in transferring technology, science and health information to journalists who write for lay audiences. But the range of exploratory TSHO index scores calculated for this sample argues for more attention to PIOs' technology/science/health orientation as predictive of their motivation to acquire more content knowledge and training. 


\section{References}

Albaek, E., Christiansen, P.M., and Togeby, L. (2003). Experts in the mass media:

Researchers as sources in Danish daily newspapers, 1961-2001. Journalism and Mass Communications Quarterly. 80(4), 937-948.

Allan, A., Ed. (2005). Journalism: Critical Issues. Thousand Oaks, CA: Sage.

American Assocation for the Advancement of Science. (2009). About Project 2061.

Retrieved on July 17, 2009 from http://www.project2061.org/about/default.htm

Anderson, A., Peterson, A. and David, M. (2005). Communication or spin? Source-media relations in science journalism. In Allan, A., ed., Journalism: Critical Issues. Thousand

Oaks, CA: Sage.

Bartlett, J. E., Kotrlik, J. W., \& Higgins, C. C. (2001). Organizational research: Determining appropriate sample size in survey research. Information Technology, Learning, and

Performance Journal, 19(1)

Bauer, M.W. and Bucchi, M. (2007). Journalism, Science and Society: Science Communication between News and Public Relations. Florence, KY: Routledge.

Beall, G.A., and Hayes, J.H.. (1992). Big, green and careful: How major California newspapers covered two ballot initiatives in the 1990 general elections. Journal of Applied Communications. 76(1), 7-11.

Beaudoin, C.E. and Thorson, E.. (2004). Social capital in rural and urban communities: Testing differences in media effects and models. Journalism and Mass Communication Quarterly. 81(2), 378-399.

Besley, J.C. and Shanahan, J. (2005). Media attention and exposure in relation to support for agricultural biotechnology. Journal of Communication. 51(4), 655-677.

Brainard, C. (2008-2009, Winter). CNN cuts entire science, tech team. Science Writers. 1,29.

Breed, W. (1955). Newspaper opinion leaders and the process of standardization. Journalism Quarterly. 32-277-284, 328.

Bruening, T.H. and Martin, R.A.. (1992) Farmer perceptions of soil and water conservation issues: implication to agricultural and Extension education. Journal of Agricultural

Education. 32(1), 48-55.

Bruening, T.H., Radhakrislma, R.B., and Rollings, T.J.. (1992). Environmental issues: Farmers' perceptions about usefulness of informational and organizational sources. Journal of Agricultural Education. 32(3), 34-44.

Bruno, F. and Vercellesi, L. (2002, January). Science information in the media: An academic approach to improve its intrinsic quality. Pharmacological Research, 45(1), 51-55.

Calamai, P. (2008, December 23). Tragedy of the media commons. Re\$earch Money. 22(20).

Retrieved on July 17, 2009 from http://www.sciencemediacentre.ca/docs/smc_calamai_rm_e.pdf 
Cassidy, A. (2004). Popular evolutionary psychology as public science and boundary work.

Proceedings of the PCST International Conferences. Retrieved July 27, 2005, from http://www.pcst2004.org.

Chermak, S. (1995). Image control: How police affect the presentation of crime news. American Journal of Police. XIV(2), 21-43.

Cooper, C.P. and Yukimura, D. (2002). Science writers' reactions to a medical "breakthrough" story. Social Science \& Medicine, 54.

Craft, S. and Wanta, W. (2004). Women in the newsroom: Influences of female editors and reporters on the news agenda. Journalism and Mass Communication Quarterly. 81(1), 124 138.

Dearing, J.W. and Rogers, E.M. (1996). Agenda-setting. Thousand Oaks, CA: Sage Publications.

DeFleur, M.L. and Ball-Rokeach, S.. (1989). Theories of Mass Communication. Fifth Edition. London: Longman.

Dillman, D.A. (2000). Mail and Internet Surveys: The Tailored Design Method. Danver, MA: John Wiley \& Sons.

Dunwoody, S. (1978). From a journalist's perspective: Putting content into mass media science writing. The English Journal. 67(4), 44-47.

Dunwoody, S. (1979). News-gathering behaviors of specialty reporters: A two-level comparison of mass media decision-making. Newspaper Research Journal. 1(1), 29-41.

Dunwoody, S. (1980). The science writing inner club: A communication link between science and the lay public. Science, Technology, \& Human Values, 5(Winter), 14-22.

Ericson, R., Baranek, P. and Chan, J. (1993). Negotiating control: A study of news sources. Canadian Journal of Communication. 18(1). Retrieved July 27, 2005, from http://www.cjconline/viewstory.pho?id=156.

Field, A. (2009). Discovering Statistics Using SPSS, $3^{\text {rd }}$ Edition. London: Sage.

Gandy, O.H. Jr. (1982), Beyond agenda setting: Information subsidies and public policy. Norwood, NJ: Ablex Publishing Company.

Grantham, S. and Irani, T. (2004). Watch your language: Translating science-based research for public consumption. Journal of Applied Communications. 88, 43-50.

Havick, J. (1997). Determinants of national media attention. Journal of Communication, 47(2), 97.

Haygood, J., Hagins, S., Akers, C., and Keith, L.. (2002). Associated Press wire service coverage of agricultural issues. NAERC Proceedings. Retrieved July 27, 2005 from http://aaaeonline.ifas.ufl.edu/NAERC/2002/naercfiles/NAERC/Associated\%Press\%20Haygo od-Hagins-Aker-Keith.pdf. 
Hays, R.G.. (1993). Trends in urban newspaper use of farm news: A qualitative study. Journal of Applied Communications. 77(2), 18-30.

Heinrichs, H. and Peters, H.P. (2004). Media communication on climate change and coastal protection: Reception and interpretations by the audience. Proceedings of the PCST International Conference. Retrieved July 25, 2005 from http://www.pcst2004.org

Holland, E. (2009). Research, not Relations. Why scientists should leave communicating to the pros. [Electronic version, published 9 September 2009]. Columbia Journalism Review Observatory.

Retrieved March 30, 2010 from http://www.cjr.org/the_observatory/research_not_relations.php

Katz, S.B. (2004). Language and persuasion in biotechnology communication with the public:

How to not say what you're not going to not say and not say it. AbBioForum. 4(2). Retrieved July 19, 2009 from http://www.agbioforum.missouri.edu/v4n2/v4n2a03-katz.htm.

King, D. (1991). Is it the sweet siren of technology or just an ill wind? Journal of Applied Communications. 75(1), 49-55.

Lee, S.T.. (2004). Lying to tell the truth: Reporters and the social context of deception. Mass Communication and Society. 7(1), 97-120.

Levin, D.Z., Cross, R. \& Abrams, L.C. (2002). The strength of weak ties you can trust: the mediating role of trust in effective knowledge transfer. Best Papers Proceedings of the Academy of Management. 1-39.

Logan, R.A.. (2001). News compartmentalization: Implications for food biotechnology coverage. AgBioForum. 4(3\&4), 119-130.

Long, M. (1995). Scientific explanation in US newspaper science stories. Public Understanding of Science. 4, 119-130.

McCombs, M. and Shaw, D. (1976). Structuring the "unseen environment." Journal of Communication. 26, 18-23.

McInerney, C., Bird, N., and Nucci, M.. (2004). The flow of scientific knowledge from lab to lay public. Science Communication. 26(1), 44-74.

McQuail, D. (1994). Mass Communication Theory. Third edition. Thousand Oaks, CA: Sage Publications.

Meyer, G. (2006, June 6). Journalism and science: How to erode the idea of knowledge. Journal of Agricultural and Environmental Ethics. 19(3).

Mormont, M. and Dasnoy, C. (1995). Source strategies and the mediatization of climate change. Media, Culture \& Society. 17, 49-64.

Morelle, R. (2005, March). Science and the media: Poles apart? Science Media Center. Retrieved July 20, 2009 from http://www.sfam.org.uk/pdf/features/scimedia.pdf.

Nisbet, M.C. \& Scheufele, D. (200). What's next for science communication? Promising directions and lingering distractions. American Journal of Botany, 96(10)., 1-12. 
Nordstrom, P.A., Wilson, L.L., Richards, M.J., Coe, B.L., Fivek, M.L., and Brown, M.B.. (1999). Student attitudes toward animal-derived products and services and how they affect society and the environment. Journal of Agricultural Education. 40(4), 10-19.

Oskam, J.B. (1992). Fields of danger: Communicating agricultural safety and health information. Journal of Applied Communications. 76(2), 1-8.

Ott, R.L. \& Longnecker, M. (2001). An introduction to statistical methods and data analysis.

Pacific Grove, CA: Duxbury-Thomson Learning.

Peters, H.P. (2009, Jun 26). Mass media as an information channel and public arena. Franklin

Pierce Law Center Media Papers. Retrieved July 19, 2009 from http://www.piercelaw.edu/risk/vol5/summer/peters.htm.

Peters, H.P., Brossard, D., de Cheveigne, S., Dunwoody, S., Kallfass, M., Miller, S., et al. (2008).

Policy forum: Interactions with the mass media. Science, 321 (5886), 204-205.

Project for Excellence in Journalism. (2008). The state of the news media 2008: An annual report on American journalism. Retrieved on July 17, 2009 from

http://www.stateofthemedia.org/2008/ narrative_newspapers_newsinvestment.php?cat $=5 \&$ media $=4$.

Ramsey, S. (1999). A benchmark study of elaboration and sourcing in science stories for eight American newspapers. Journalism \& Mass Communication Quarterly, 76(1).

Reber, B.H. and Berger, B.K.. (2005).Framing analysis of activist rhetoric: How the Sierra Club succeeds or fails at creating salient messages. Public Relations Review. 31, 185-195.

Rodriquez, L., Farnall, O., Geske, J. and Peterson, J.W.. (1998). Opinion formation on environmental protection: Understanding the origins of attitudes toward resource enhancement and protection in Iowa. Journal of Applied Communications.,82(2), 27-45.

Rogers, E.M. and Dearing, J.W. (2000). Agenda-setting research: Where has it been, where is it going? Media Power in Politics.

Rhomberg, M. (2009). The mass media and the risk communication of climate change: A theoretical observation. Friedrichshafen, Germany: Zeppelin University.

Sachsman, D.B.. (1993). Communication between scientists and the media: Introducing the concepts of risk, risk analysis, and risk communication for reporters. Proceedings of the Hazardous Waste Conference. Retrieved July 28, 2005, from http://www.atsdr.cdc.gov/cx12c.html. Scheufele, D.A. (1999). Framing as a theory of media effects. Journal of Communication. 49(1), 103-122.

Schultz, T. (2002). Does education matter? Characteristics of journalists who went to graduate school. Journalism. 3(2), 223-238

Shoemaker, P.J., Eichholz, M., Kim, E. and Wrigley, B. (2001). Individual and routine forces in gatekeeping. Journalism \& Mass Communication Quarterly. 78, 233-246. 
Simonson, P. (1999). Mediated sources of public confidence: Lazarsfeld and Merton revisited.

Journal of Communication. 49(2), 109-122.

Sperbeck, J.M. (1997). Some media relations success stories. Journal of Applied Communications. 81(3), 24-39.

Sumpter, R.S. and Braddock, M.A. (2002). Source use in a "news disaster" accounting: A content analysis of voter news service stories. Journalism \& Mass Communication Quarterly. 79(3), 539-558.

Ten Eyck, T.A.. (2000). The marginalization of food safety issues: An interpretative approach to mass media coverage. Journal of Applied Communications. 84(2), 29-46.

Tewksbury, D., Jones, J., Peske, M.W., Raymond, A. and Vig, W. (2000). The interaction of news and advocate frames: Manipulating audience perceptions of a local public policy issue. Journalism \& Mass Communication Quarterly. 77(4), 804-829.

Triese, D. and Weigold, M.F. (2002). Advancing science communication: A survey of Science communicators. Science Communication. 23: 310-322

Valenti, J.M. (1999). How well do scientists communicate to media? Science Communication. 21(2), 172-178.

Vestal, T.A. and Briers, G.E.. (1999). Metro news journalists critique food biotechnology. Journal of Applied Communications. 83(2), 22-34.

Wilcox, D. (2005). Public Relations: Writing and Media Techniques. Fifth Edition. Boston, MA: Pearson AB.

Wingenbach, G.J., Rutherford, T. and Dunsford, D.W. (2003). Agricultural communications students' awareness and perception of biotechnology issues. Journal of Agricultural Communications. 44(4), 80-93. 